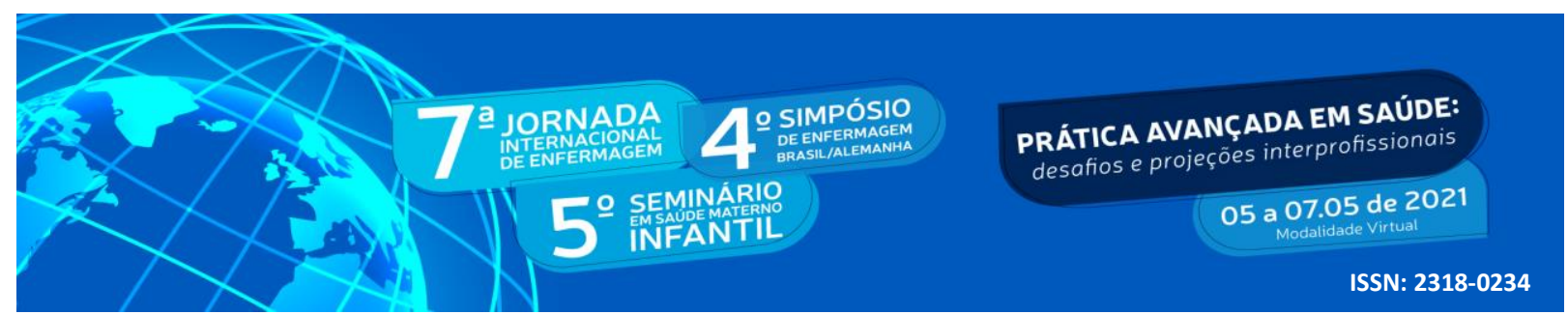

\title{
VIVÊNCIAS DE ADOLESCENTES GESTANTES DIANTE DO CICLO GRAVIDICO PUERPERAL
}

\section{Patrício de Almeida Costa ${ }^{1}$; Marluce Costa Silva ${ }^{2}$; Maria Paula Barbosa Ramalho ${ }^{3}$; Layla Caroline Lino da Silva ${ }^{4}$; Cayane Maria da Silva Santos ${ }^{5}$; Nathanielly Cristina Carvalho de Brito Santos ${ }^{6}$}

\begin{abstract}
RESUMO
Objetivo: analisar as vivências de adolescentes gestantes atendidas em unidades de Saúde da Família diante do ciclo gravídico puerperal. Método: estudo exploratório, qualitativo, realizado nas Unidades urbanas de Saúde da Família um município do Curimataú Paraibano, com 11 adolescentes grávidas acompanhadas no pré-natal pelos profissionais de saúde. Os dados foram coletados de janeiro a março de 2018, por entrevista semiestruturada, e tratados pela análise de conteúdo. Resultados: A análise resultou na construção da categoria temática "Vivências de adolescentes gestantes diante do ciclo gravídico puerperal", e as subcategorias: 1. Sentimentos positivos diante do apoio familiar e, 2. Dificuldades enfrentadas. Conclusão: Constatou-se a necessidade de os profissionais de saúde estarem capacitados para ofertar um cuidado concatenado as necessidades desse público. Portanto, fortalecer o vínculo e promover uma assistência à adolescente-filho-família no contexto da integralidade em saúde.
\end{abstract}

Palavras-chave: Adolescente; Atenção Primária à saúde; Gravidez.

\begin{abstract}
Objective: to analyze the experiences of pregnant adolescents attended at Family Health units about pregnancy and the care received during prenatal care. Method: exploratory, qualitative study, carried out in the urban Family Health Units of Cuité, Paraíba, with 11 pregnant adolescents monitored in prenatal care by health professionals. Data were collected from January to March 2018, through semistructured interviews, and analyzed by content analysis. Results: The analysis resulted in the construction of the thematic category "Experiences of adolescents about pregnancy and prenatal care" and two subcategories: "Positive feelings towards family support. Conclusion: There was a need for health professionals to be trained to offer care concatenated to the needs of this public. Therefore, strengthen the bond and promote assistance to the adolescent-child-family in the context of integrality in health.
\end{abstract}

Key Words: Adolescent; Pregnancy; Primary Health Care.

\footnotetext{
1 Graduando em Enfermagem pela Universidade Federal de Campina Grande - Campus Cuité. E-mail: patricioalmeida13@hotmail.com

2 Enfermeira pela Universidade Federal de Campina Grande - Campus Cuité. E-mail: marlucemcssilva@gmail.com

3 Graduanda em Enfermagem pela Universidade Federal de Campina Grande - Campus Cuité. E-mail: ramalhobarbosa61@gmail.com.

4 Graduanda em Enfermagem pela Universidade Federal de Campina Grande - Campus Cuité. E-mail: layla.carol.lino.s2@hotmail.com.

5 Graduanda em Enfermagem pela Universidade Federal de Campina Grande - Campus Cuité. E-mail: cayanemaria3@gmail.com

${ }^{6}$ Orientadora. Doutora em Enfermagem pela Universidade Federal da Paraíba (UFPB). E-mail: nathanielly.cristina@professor.ufcg.edu.br
} 


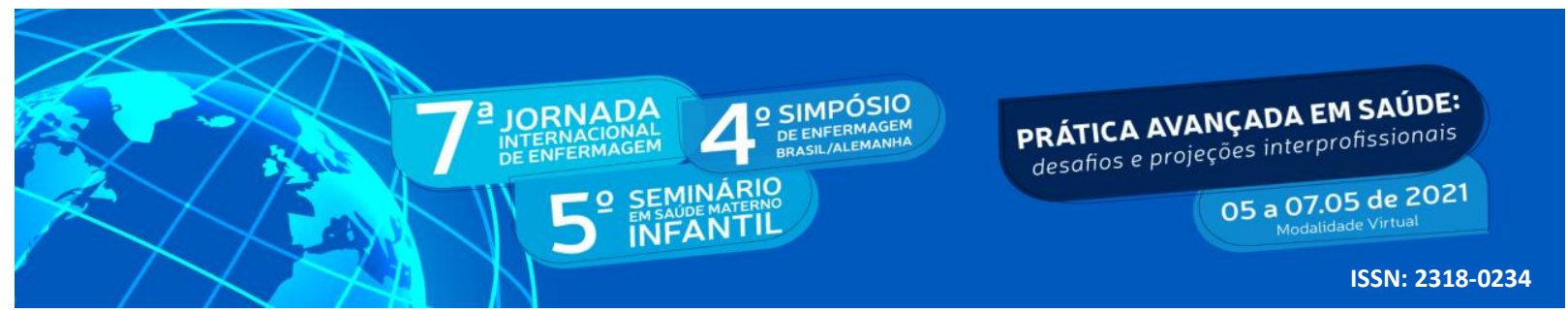

\section{INTRODUÇÃO}

A adolescência é compreendida como um período de transição entre a infância e a fase adulta, cronologicamente delimitada pela Organização Mundial de Saúde (OMS) entre a faixa etária de 10 e 19 anos de idade. Trata-se de uma fase marcada por significativas mudanças no processo de crescimento e desenvolvimento biopsicossocial, no qual se insere o despertar para vivência da sexualidade e a prática sexual, que constitui um fator de risco para gravidez não planejada ou precoce (SILVA; ABRÃO, 2020).

A gravidez na adolescência representa um problema de saúde pública mundial. De acordo com a Organização das Nações Unidas (ONU), no mundo, para cada mil nascimentos, 46 deles são frutos de gestantes de 15 a 19 anos de idade, uma média consideravelmente alta. No contexto nacional, o Brasil supera essa estimativa mundial, elevando, em seu território, a taxa para 68,4 nascimentos, o que supera a taxa prevista na América Latina e no Caribe, os quais apresentam uma estimativa de 65,5 nascimentos respectivamente (SILVA; ABRÃO, 2020).

Salienta-se que, a gravidez precoce é considerada um fenômeno transformador, tendo em vista que desencadeia, na adolescente, mudanças biopsicoemocionais, como também familiar e social, o qual podem comprometer o desenvolvimento materno e fetal saudável. Logo, se faz necessário uma atenção em saúde humanizada e um olhar cuidadoso, com escuta e acolhimento qualificado por parte de toda a equipe multiprofissional, para que seja possível a criação de vínculo com a adolescente, e assim, uma assistência integral e efetiva (CECAGNO et al., 2020; SILVA; ENGSTROM, 2020).

Para tanto, os profissionais da Atenção Primária à Saúde (APS) que atuam no âmbito das Unidades de Saúde da Família (USF) devem acolher esse público e cumprir o seu papel de ponto de entrada das Redes de Atenção à Saúde (RAS) e de coordenadora de um cuidado qualificado à adolescente (SILVA; ENGSTROM, 2020).

No entanto, estudos evidenciaram que a atenção à adolescente em período gravídico, ainda consiste um desafio para a equipe de saúde, pois limitações na adequação da linguagem e forma como atuam no cuidado a esse grupo, somado as incipientes ações de promoção da saúde e prevenção de doença e agravos, contribuem para fragilidade na interação e formação de vínculos desses com os profissionais, o que dificulta a procura pelos serviços de saúde de 


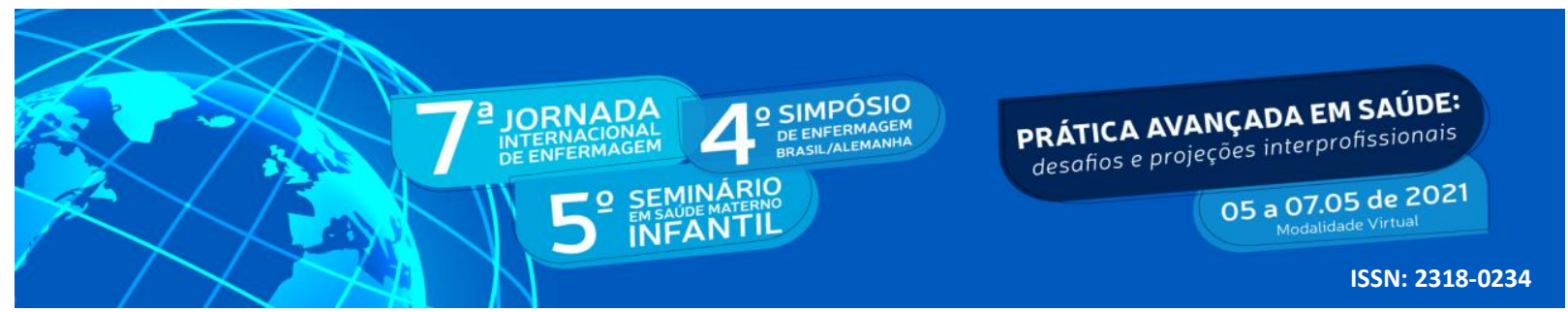

forma preventiva e compromete a integralidade do cuidado (PITILIN; FERNANDES;SILVA FILHO, 2017).

Considerando a importância de uma atenção à saúde de qualidade às adolescentes durante seu período gestacional, justifica-se a necessidade de se obter uma visão ampliada da gravidez precoce, a partir da percepção de quem vivencia o fenômeno, vislumbrando-se contribuir para uma assistência com capacidade de avaliar e entender o contexto biopsicossocial da adolescente, e implementar ações direcionadas às suas especificidades. Ante o exposto, surgiu como questão norteadora: Qual a vivência da adolescente gestante diante do ciclo gravídico puerperal?

\section{OBJETIVO}

Analisar as vivências de adolescentes gestantes atendidas em Unidade de Saúde da Família diante do ciclo gravídico puerperal.

\section{METODOLOGIA}

Trata-se de um estudo qualitativo, exploratório, como parte de uma pesquisa maior intitulada "Vivências de gestantes adolescentes durante a gravidez e o acompanhamento prénatal" realizada no período de janeiro a março de 2018, em uma das Unidades Básicas de Saúde (UBS) veiculada a Estratégia Saúde da Família (ESF) em um município no Curimataú Paraibano, Brasil.

A seleção das participantes ocorreu por amostragem sistemática a partir de uma lista elaborada com a relação das gestantes cadastradas em cada uma das referidas unidades de ESF. Ao final, o estudo contou com a participação de 11 adolescentes grávidas adscritas e realizando acompanhamento pré-natal, pelos profissionais médico e/ou enfermeiro do referido município.

A coleta de dados foi realizada por meio da técnica de entrevista, guiada por um roteiro semiestruturado contendo dados de identificação das participantes e questões norteadoras sobre a temática de interesse. Na oportunidade, a pesquisadora responsável apresentou os Termos de Assentimento (TA) e de Consentimento Livre e Esclarecido (TCLE) contendo os objetivos, benefícios e riscos da pesquisa. Aquelas menores de 18 anos, que assinaram o TA, somente poderiam participar após anuência do seu responsável, por meio da assinatura do TCLE.

As entrevistas foram realizadas no âmbito do domicílio de cada adolescente, em data e horário previamente agendados, respeitando a conveniência de cada participante. Foram 


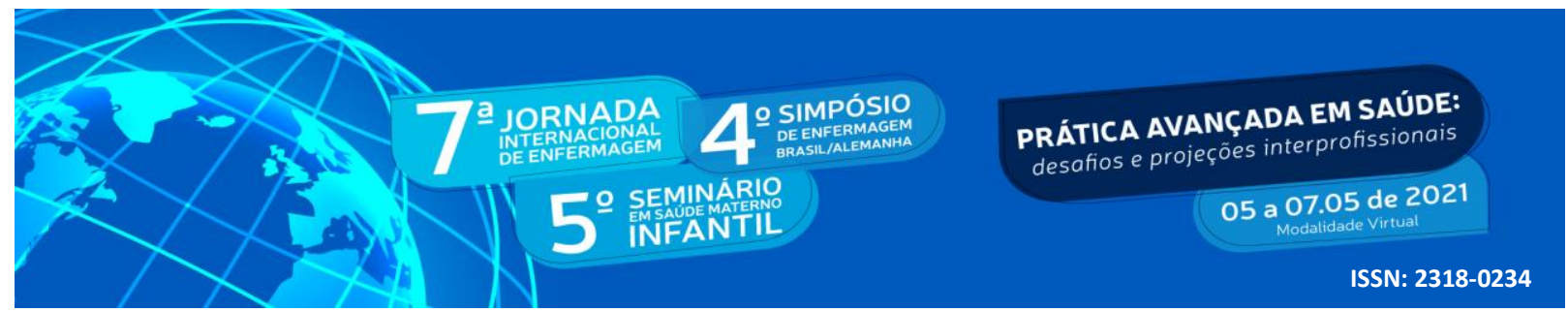

realizadas de forma individual, gravadas com o auxílio de um aparelho MP3 player, e, posteriormente, transcritas na íntegra para garantia da fidedignidade das informações. Para garantia do anonimato, cada uma das participantes foi identificada pela letra "G" seguida da ordem de entrevista. $\mathrm{O}$ encerramento da coleta de dados se deu por saturação, ou seja, quando o material empírico começou a apresentar repetições nas respostas em relação ao objetivo proposto.

A análise dos dados foi realizada por meio da técnica de análise de conteúdo, que prevê como etapas: pré-análise: consiste em uma organização do material, a partir da escolha de documentos/informações importantes, permitindo bom entendimento; exploração do material: que visa alcançar a compreensão do texto, o que exige a categorização por meio da redução do texto às palavras e expressões significativas; e tratamento dos resultados obtidos e interpretação: busca realizar as interpretações dos dados a partir da literatura pertinente (MINAYO, 2017). Para o presente estudo foram selecionadas duas categorias de análise para construção do recorte da pesquisa.

Quanto aos aspectos éticos, à pesquisa obedeceu aos pressupostos da Resolução $\mathrm{n}^{\circ}$ 466/2012 do Conselho Nacional de Saúde (CNS) que trata de pesquisas com seres humanos, sendo aprovada sob parecer $\mathrm{n}^{0}$ 2.360.764 do Comitê de Ética do Hospital Universitário Alcides Carneiro (CEP/HUAC).

\section{RESULTADOS E DISCUSSÃO}

\section{Caracterização das participantes}

Participaram desta pesquisa 11 adolescentes grávidas, com idade de 15 a 19 anos, cujos dados perinatais expressaram idade gestacional variando entre 08 e 39 semanas, com número de uma a três gestações. Em relação ao planejamento reprodutivo, sete delas não utilizavam nenhum método contraceptivo antes de engravidar. No que concerne à frequência escolar, cinco deixaram de ir à escola com a descoberta da gestação.

A análise do material empírico possibilitou a construção da categoria temática "Vivências de gestantes adolescentes sobre a gravidez" e duas subcategorias apresentadas a seguir:

\section{Sentimentos positivos diante do apoio familiar}




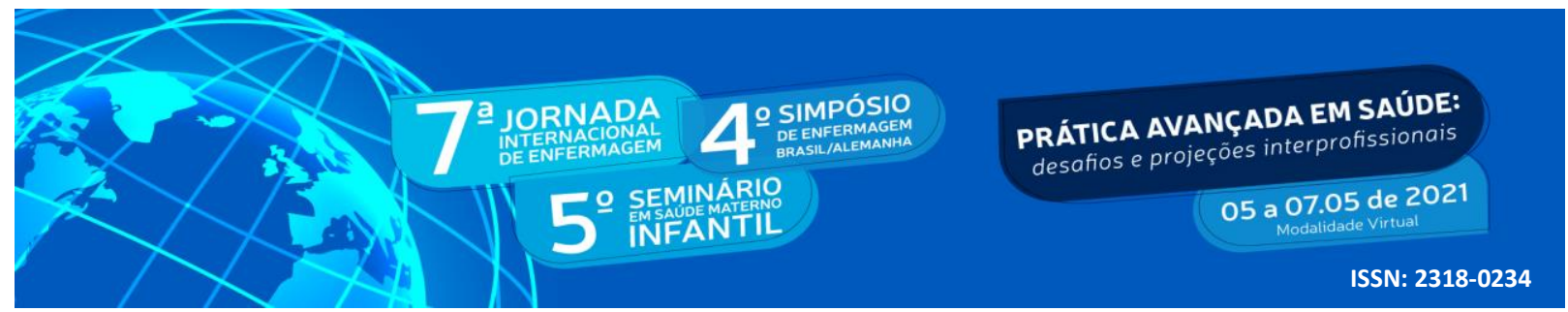

No estudo em tela, foi possível perceber que as adolescentes gestantes apresentaram nessa vivência sentimentos de alegria, tranquilidade e felicidade diante do apoio do parceiro e da família nesse momento.

[...] muito bom! Tô compartilhando também com a minha família. Tá todo mundo muito alegre..., minha mãe sempre vem às consultas comigo. (G1) O meu período gestacional é bem tranquilo. Eu não sei se é porque eu tive apoio da família e, também, eu vivo em uma união estável, então tudo é mais fácil. Ele me ajuda muito. É um marido excelente, não tenho de que reclamar. Então, [...] tudo, sendo tranquilo. (G2)

Bem, durante esse tempo que eu descobri até agora, tá sendo muito bom pra mim, felicidade enorme. Uma que um filho sempre é uma bênção e eu tô muito feliz [...]. (G10)

[...] esse momento [...] é muito maravilhoso, principalmente essa minha segunda gravidez, porque eu tenho o pai do meu lado [...]. Então, pra mim, tá sendo maravilhoso. Na minha primeira, o pai era bem distante porque a gente nunca deu certo, e esse a gente se dar super bem. (G9)

Nota-se que a descoberta da gravidez pela adolescente desencadeia uma série de sentimentos que acabam afetando de forma significativa sua vida, bem como de sua família. A cooperação e o interesse por parte dos familiares nesse período de mudanças merecem destaque, uma vez que, essas atitudes tornam-se condições fortalecedoras para o enfrentamento da gestação por essas adolescentes, possibilitando que tanta a gravidez quanto o período pós-parto transcorram de forma tranquila e saudável (MARANHÃO et al., 2018).

Ademais, quando a adolescente encontra subsídio na família e no parceiro para enfrentar à gestação é possível seguir com uma maternidade mais segura, confiante, e mesmo que não tenha planejado esse momento, elas conseguem dar continuidade de forma desejada e com motivação para cuidar de seus filhos (SANTOS et al., 2015).

Em contraponto, a ausência do apoio familiar pode desencadear na adolescente o desinteresse consigo e com a gestação, interferindo nas atividades cotidianas de autocuidado, bem como na adesão ao pré-natal, potencializando assim, sua vulnerabilidade biopsicossocial (SANTOS et al., 2015).

Logo, faz-se necessário refletir sobre a atuação dos profissionais que acompanham a gestante adolescente no cuidado pré-natal, e como interagem com a família para sensibilização 


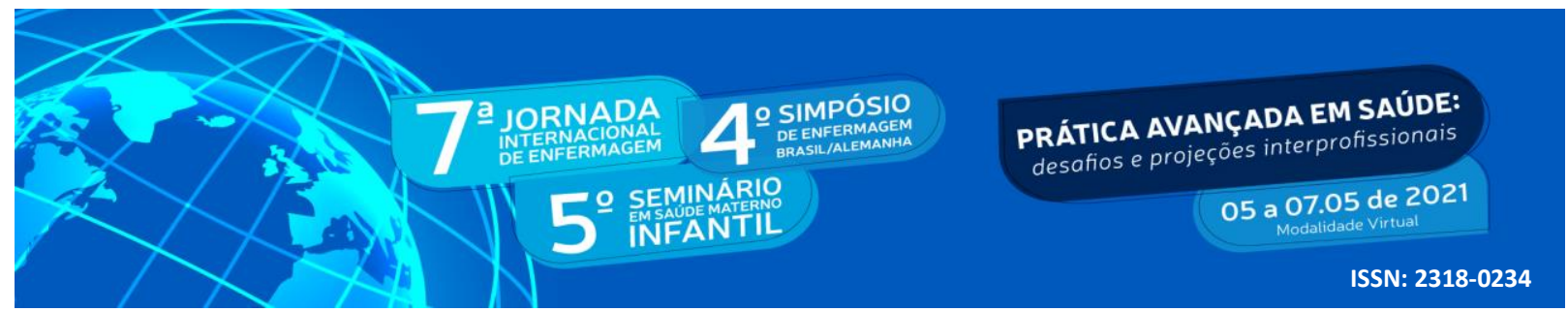

diante do desenvolvimento de todos em prol do cuidado à mãe e à criança que vai chegar, de modo a minimizar situações que venham comprometer o desenvolvimento biopsicossocial da adolescente que vivencia a gestação.

\section{Dificuldades enfrentadas}

Por conseguinte, percebe-se que apesar de não se sentirem sozinhas nesse momento, ainda vivenciam dificuldades para continuar a rotina à priori existente, principalmente, em relação aos estudos.

Deixei de estudar por causa da gravidez e porque meu marido também não deixou que fosse pra escola mais não. (G3) [...] eu parei de estudar já [...] faz dois anos, por causa da minha menininha, [...]. (G5)

Eu não estudo não. Deixei de estudar na primeira gestação. [...] eu passei 3 anos sem estudar e voltei em 2016 e reprovei. Em 2017, voltei a estudar, mas parei, parei porque eu quis mesmo, mas eu pretendo voltar a estudar. (G7)

Quando eu descobri [...] tava de férias. Aí eu não voltei mais, porque, [...] eu tinha que interromper no meio do ano, [...], eu achei melhor. E, eu, também, sentia muito enjoo, eu tava muito fraca [...], eu não quis voltar. Mas eu pretendo voltar à escola daqui a um ano. Quando ele tiver com um aninho, [...], eu volto. (G8)

No que concerne às dificuldades vivenciadas das participantes, observa-se que a gravidez na adolescência contribui diretamente para evasão escolar, pois o cuidado com a criança torna-se prioridade, e assim, não se tem tempo para frequentar a escola ou com quem deixar o(s) filho(s) para isso. Logo, é oportuno destacar que problemas no contexto social e familiar, bem como a sobrecarga no cuidado à criança acarretados após o parto, são fatores determinantes no comprometimento do retorno das adolescentes aos estudos, o qual acaba gerando consigo um consequente grau inadequado de escolaridade pelas mesmas (SILVA et al., 2020).

Outrossim, algumas mães acabam optando por estudar no período da noite, o que não é aceito por alguns companheiros que por ciúmes e/ou falta de confiança, demonstrando "poder" sobre as adolescentes as impedindo de frequentar a escola. Além disso, mesmo em ambientes nos quais os companheiros (os pais do bebê) apoiam as adolescentes, as mesmas, por muitas 


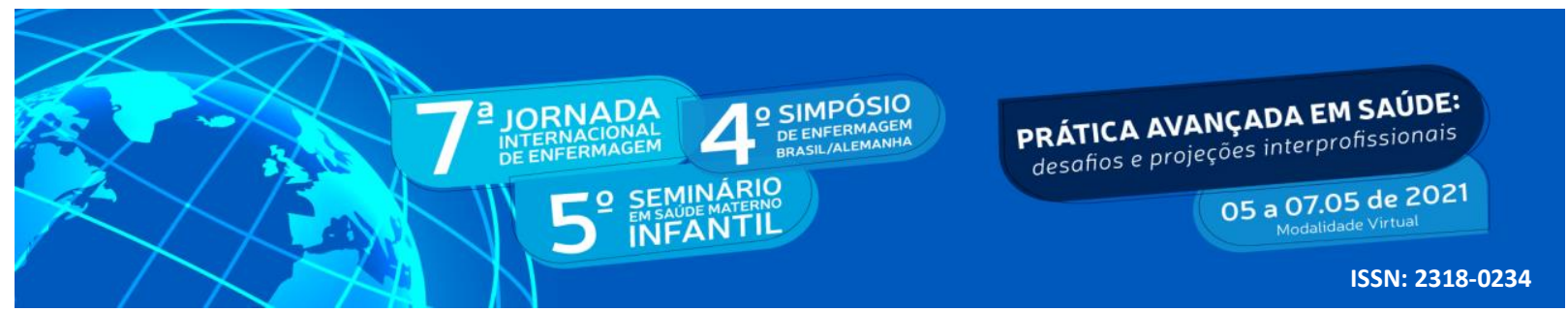

vezes, optam por se dedicar a atividades remuneradas e complementares da renda familiar (SILVA et al., 2020).

Na discussão apresentada é pertinente atentar para o fato de que a evasão escolar e até a falta de interesse pela escolarização, comuns no contexto da maternidade na adolescência, pode ocorrer devido ao alto índice de reprovações dessas gestantes durante o período gravídico, favorecendo assim a desmotivação dessas adolescentes na continuação do processo de escolarização e capacitação profissional (MULLER et al., 2018). O que desperta reflexões sobre a influência dessas condições na reincidência da gravidez na adolescência.

Outra dificuldade observada a partir das falas das participantes é referente à aceitação da nova condição "ser gestante", pois relataram desde surpresa diante da confirmação, pensamento de praticar aborto e se ver livre da situação, até conformismo com a circunstância.

Mulher, no começo eu fiquei meio assim, sabe? Porque a minha menina só tava com 1 ano e 3 meses. [...] eu fiquei meia assim. Pensei até em tirar, sabe? Só que a minha mãe não apoia essas coisas. Ela ainda apoiou do primeiro, mas desse aqui não, nem ela, nem o meu irmão. [...] depois eu aceitei, mas no começo da gravidez eu não aceitava. Tive que ir me acostumando e aceitando aos poucos. (G5)

Mas, eu não queria que fosse agora, porque eu já tenho uma menina. (G6) [...] porque eu só queria um filho depois, dez anos depois da outra, aí, veio logo assim, com a menina ainda com 5 anos. (G7) Meu esposo se assustou, assim como eu [...]. A gente falava em ter um filho, só que lá pra frente e não... não era agora. (G8)

É uma fase né, que.... eu queria voltar atrás, porque eu não queria engravidar e muito menos eu queria namorar com esse menino porque eu não gostava dele [...]. Até agora eu não tive nenhuma sensação, porque eu não gosto do bebê, pra falar a verdade eu não gosto, mas mainha disse que a pessoa só aprende a gostar depois que ele nasce, a pessoa vai se apegando mais, diz ela, mas pra mim é como se eu tivesse a minha vida normal. No começo eu pensei em tirar, mas a minha mãe proibiu. Ela gosta muito e depois que ela descobriu que é menino, aí, que ela gostou mesmo. (G11).

Em relação à nova gestação ainda em idade precoce, chama a atenção o fato de estar nítido o desejo de não engravidar por já terem filho, ao mesmo tempo em que demonstraram falha no uso do método contraceptivo. Isso pode sugerir que a vivência de uma gestação e as 


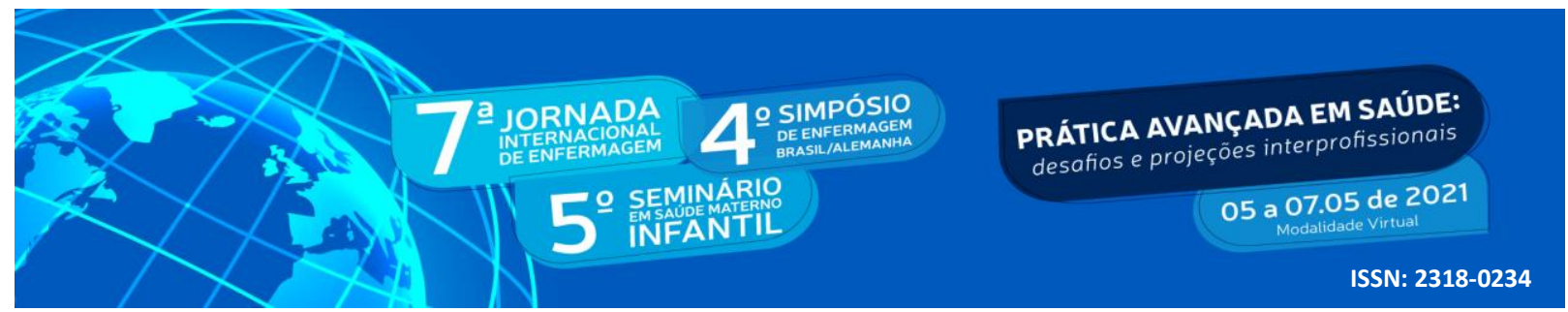

repercussões para a vida da adolescente pode não ser capaz de impedir a repetição da situação, além do que, a adesão ao planejamento reprodutivo pode não ser uma realidade homogênea entre as adolescentes.

Embora o acesso aos métodos contraceptivos e ao planejamento reprodutivo sejam ações amplamente disponíveis nas unidades de ESF, as adolescentes pouco procuram os serviços para esse fim. Por outro lado, os profissionais de saúde encontram dificuldades na forma de abordar as adolescentes, o que pode comprometer a realização da consulta e adesão às ações. Sendo necessário o planejamento de estratégias que identifiquem os fatores comprometedores desse processo e que favoreçam a procura e acesso desse público aos serviços de saúde. (VICENTIM et al, 2019).

O planejamento reprodutivo deve ser contemplado na adolescência para uma experiência de vida sexual e reprodutiva saudável. Logo, é papel da atenção primária em saúde o desenvolvimento de ações programáticas, em âmbito individual ou coletivo, que abranjam essa população, no intuito de educar, prevenir e sensibilizá-los para uma sexualidade segura e controle do índice de gravidez na faixa etária (VICENTIM et al, 2019).

Por conseguinte, chama a atenção com preocupação o fato de entre as dificuldades apontadas está o pensamento de interromper a gravidez. O medo de não ter o apoio do parceiro, a não aceitação ou rejeição da gravidez e até mesmo o desespero devido ao impacto da notícia são alguns dos motivos que levam a adolescente a praticar o aborto, como uma forma de solucionar a situação e tentar fugir da realidade (RODRIGUEZ, 2017; MARANHÃO et al., 2018).

A chance de provocar o aborto aumenta com o número de gestações, e que, quando a adolescente não compartilha esse momento com a família, torna-se mais propensa a tomar decisões isoladas e precipitadas (RODRIGUEZ, 2017; MARANHÃO et al., 2018).

Nesse contexto, de não aceitação da gestação, há evidência das influências das percepções negativas das adolescentes ao descobrirem a gravidez, devido ao não planejamento e por enxergar a mesma como interrupção de planos futuros e por ter acontecido em um momento inoportuno, de forma acidental, afirmativa corroborada pelo estudo em tela (SILVA et al., 2020). 


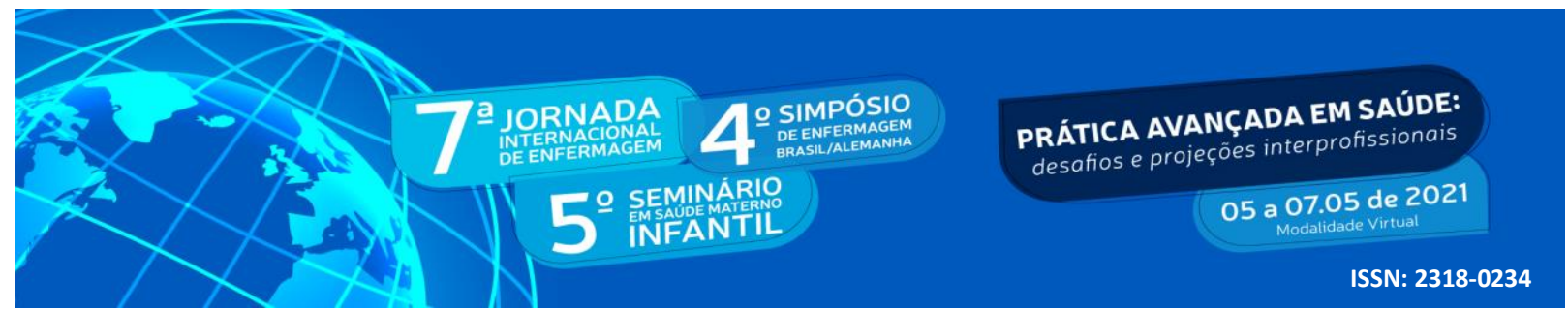

Por isso, exige-se um a consulta de pré-natal por profissional, que possibilite um contato mais significativo com a adolescente gestante, de modo a oferecer um cuidado holístico e integral, com modelo terapêutico imbuído de um olhar para os aspectos afetivos, considerando sentimentos e emoções vivenciados nesse período (VICENTIM et al, 2019), como cerne para tomada de decisão sobre estratégias e condutas em tempo oportuno.

\section{CONCLUSÃO}

A partir das vivências de adolescentes gestantes atendidas, percebe-se que apesar desse assunto causar impacto no âmbito familiar, não impede o apoio da família e do companheiro. No entanto, deixar de frequentar a escola, vivenciar a gravidez recorrente, e expressar desejo de interromper a gestação são dificuldades observadas em grande frequência, exigindo atenção por parte dos profissionais para um cuidado integral à saúde da adolescente gestante.

Portanto, é importante frisar a necessidade de os profissionais de saúde estarem capacitados para ofertar um cuidado concatenado às necessidades desse público com intervenções que possibilitem à adolescente confiança para expressar sentimentos e esclarecer dúvidas, além de fortalecer o vínculo e promover uma assistência efetiva.

Apesar das limitações observadas na pesquisa no que concerne a realização da entrevista perante a timidez das participantes, como esperado nessa fase, vislumbra-se como contribuição, que este estudo possa contribuir para as práticas baseadas em evidência científica. E, assim, despertar reflexões de pesquisadores, gestores e profissionais de saúde sobre as competências necessárias para o cuidado e as estratégias de promoção da saúde da adolescente gestante, filho e sua família no contexto da integralidade em saúde.

\section{REFERÊNCIAS}

CEGANO, S. et al. Fatores obstétricos relevantes na adolescência: uma revisão integrativa no contexto nacional e internacional. Arq. Ciências da Saúde da UNIPAR. Umuarama, v. 24, n. 3, p. 197-202, set-dez. 2020. Disponível em:< https://revistas.unipar.br/index.php/saude/article/view/7557/4018>. Acesso em: 11. mar. 2021.

MARANHÃO T.A. et al. Atitudes e reações familiares e sociais diante da gravidez na adolescência. REUOL. Recife, v. 12, n.4, p.840-880, abr., 2018. Disponível em:< https://periodicos.ufrn.br/interlegere/article/download/4873/4272/>. Acesso em: 12 mar. 2021. 


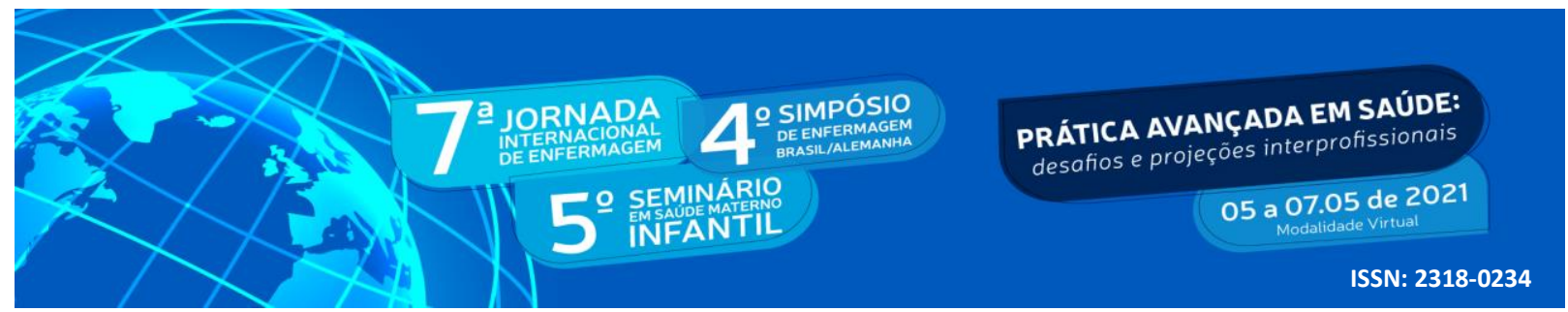

MINAYO, M.C.S. O desafio do conhecimento: Pesquisa qualitativa em saúde. 13. ed. São Paulo: Hucitec, 2010. Disponível em:< https://pesquisa.bvsalud.org/portal/resource/pt/biblio970388 > Acesso em: 13. mar.2021

MULLER, T.L. et al. Aspectos Sociodemográficos e Escolares de Gestantes Adolescentes: Gravidez e Evasão Escolar. Psicologia \& Educação. Porto Alegre, v.1, n.1, p.44-57, 2018. Disponivel em:< http://psicologiaeeducacao.ubi.pt/Files/Other/Artigos\%20OnLine/2018/V1N1\%20online/5.\% 20V1N1online2018.pdf>. Acesso em 07 mar. 2021

PINTILIN, E.B.; PELLOSO, S.M. Internações sensíveis à atenção primária em gestantes: fatores associados a partir do processo da atenção pré-natal. Texto Contexto Enferm. Santa Catarina, v. 26, n.2, 2017. Disponível em:< https://www.scielo.br/pdf/tce/v26n2/pt_01040707-tce-26-02-e06060015.pdf>. Acesso em 10 mar. 2021.

RODRIGUES, A.R.S. et al. Reincidência da gravidez na adolescência: percepções das adolescentes. Enferm. Foco. São Paulo, v.7, n.4, p.66-70. Disponível em : <http://revista.cofen.gov.br/index.php/enfermagem/article/view/945/355>. Acesso em: 09 mar. 2021

SILVA, D.C.P. et al. Percepções e experiências de adolescentes acerca do seu processo de gravidez. Brazilian Journal of Development. Curitiba, v.6, n. 12, p.97199-97210, dez. 2020. Disponível em :< https://www.brazilianjournals.com/index.php/BRJD/article/view/21447/17114>. Acesso em 12 dez. 2021.

SANTOS, R.L.B., et al. Atenção no pré-natal de baixo risco na ótica de puérperas. Rev Enferm UFSM. Santa Catarina, v.5, n.4, p.628-37. Disponível em :<https://periodicos.ufsm.br/reufsm/article/view/16071/pdf〉. Acesso em: 11 mar. 2021

SILVA, G.V.; ABRÃO, J.L.F. Experiências emocionais da gravidez na adolescência: entre expectativas e conflitos. Boletim academia paulista de psicologia. São Paulo, v.40, n.98, p.63-72, abr. 2020. Disponível em:< https://revistas.unoeste.br/index.php/cv/article/view/3329/2960>. Acesso em: 11 mar. 2021

SILVA, R.L.; ENGESTROM, E.M. Atenção integral a saúde do adolescente pela atenção primária a saúde no território brasileiro: uma revisão integrativa. Interface. São Paulo, 2020. Disponível em :<https://www.scielo.br/pdf/icse/v24s1/1807-5762-icse-24-s1-e190548.pdf>. Acesso em: 11. mar. 2021

VICENTIM, A.L. et al. Prevenção da gravidez na adolescência no Brasil. Rev. Enfer. Brasil. São José do Rio Preto, v.18, n.4, p.582-590, 2019. Disponível em:< https://portalatlanticaeditora.com.br/index.php/enfermagembrasil/article/view/2497/pdf>. Acesso em: 09 mar. 2021 